\title{
DERIVASI BAHASA MELAYU BENGKULU
}

\author{
'Nuri Hermi Mawar Ningsih; ${ }^{2}$ Dian Eka Chandra Wardhana; ${ }^{3}$ Supadi \\ 1,2,3 Program Studi Pendidikan Bahasa Indonesia FKIP Universitas Bengkulu
}

\section{Abstrak}

\section{Korespondensi: nuri2016bkl@gmail.com}

Tujuan penelitian ini adalah untuk mengetahui dan mendeskripsikan bentuk, fungsi afiks, dan makna derivasi pada bahasa Melayu Bengkulu. Penelitian ini menggunakan metode deskriptif. Data dalam penelitian ini adalah kata-kata yang bersumber dari tuturan bahasa Melayu Bengkulu. Pengumpulan data digunakan teknik simak libat cakap. Teknik analisis data digunakan teknik top down dan bottom $u$. Hasil penelitian ini ditemukan verba yang mengandung prefiks $N$ - mengubah nomina menjadi verba, prefiks be- mengubah nomina menjadi adjektiva, prefiks temengubah nomina menjadi verba, prefiks meN- mengubah adjektiva menjadi verba, konfiks ke-an mengubah nomina menjadi adjektiva, gabungan afiks $N$-dan -kan mengubah adjektiva menjadi verba, sufiks $-i$ mengubah nomina menjadi verba, sufiks -kan mengubah adjektibva menjadi verba, sufiks -an mengubah verba menjadi nomina. Nomina yang mengandung prefiks pe- mengubah verba menjadi nomina, prefiks peN- mengubah verba menjadi nomina, konfiks per-an mengubah verba menjadi nomina, prefiks ke- mengubah adjektiva menjadi nomina, sufiks -an mengubah adjektiva menjadi nomina, konfiks peN-an mengubah verba menjadi nomina. Adjektiva yang mengandung prefiks be- mengubah nomina menjadi adjektiva, konfiks ke-an mengubah nomina menjadi adjektiva. Berdasarkan hasil penelitian data disimpulkan bahwa adanya derivasi berdasarkan bentuk, fungsi afiks, dan maknanya pada bahasa Melayu Bengkulu.

Kata kunci: derivasi, bahasa melayu bengkulu

\begin{abstract}
The purpose of this research is to find out and describe the form, function, and meaning derivation affix at Bengkulu Malay language. This research uses descriptive method. The data in this study are the words that come from Bengkulu Malay language speech. Data collection techniques used see libat ably. Technique of data analysis used the technique of top down and bottomup. The results of this study found verbs containing $N$-prefix change nouns into verbs, the prefix be-change nouns into adjectives, noun prefix te-change into verbs, the prefix meN-change adjectives into verbs, a Confix per-an change nouns into adjectives, affixes combined $N$-and - kan change adjectives into verbs,suffixes $-i$ change nouns into verbs, suffixes kanadjektibva's change into a verb, a suffix -an change the verb into a noun. The noun containing the prefix $p e$-change verbs into nouns, the prefix $p e N$-change the verb into a noun, a Confix per-an change the verb into a noun, a prefix ke-change adjectives into nouns, suffixes change -an adjectival noun, becoming a Confix penan change the verb into a noun. Adjectives containing the prefix be-change nouns into adjectives, a Confix per-an change nouns into adjectives. Based on the results of the study it was concluded that the presence of data derivation based on form, function and meaning on the affix Malay Bengkulu.
\end{abstract}

Keywords: derivation, Bengkulu Malay language 


\section{PENDAHULUAN}

Bahasa melayu Bengkulu merupakan bahasa yang digunakan oleh masyarakat provinsi Bengkulu, bahasa melayu Bengkulu sendiri termasuk ke dalam bahasa austronesia barat seperti halnya bahasa-bahasa nusantara lainnya, dimana bahasa melayu Bengkulu ini memiliki perbedaan dengan bahasa-bahasa austronesia barat yang lain. Meskipun penelitian terhadap derivasi sudah banyak dilakukan, namun pada kenyataannya masih ada penelitian yang perlu digali dan diteliti terutama dalam penelitian derivasi bahasa, salah satunya mengenai fungsi dan maknanya, dimana derivasi sendiri merupakan proses pembentukan kata yang di dalamnya terdapat fungsi dan makna dari suatu kata yang sudah mengalami afiksasi, di dalam bahasa Melayu Bengkulu sendiri terdapat afiks-afiks yang berbeda dari bahasa Indonesia maupun bahasa-bahasa yang lain, sesuai dengan latar belakang maka dari itu penelitian ini akan mendeskripsikan bentuk, fungsi dan makna derivasi bahasa Melayu Bengkulu. Selain itu dalam bahasa Melayu Bengkulu juga belum secara lengkap dijelaskan mengenai pembentukan kata yang berkategori derivasi, inilah yang membuat peneliti tertarik untuk meneliti Derivasi Bahasa Melayu Bengkulu, selain bertujuan untuk mengetahui bentuk, fungsi dan makna derivasi bahasa Melayu Bengkulu penelitian ini juga yang nantinya akan menambah wawasan dalam derivasi pada bahasa melayu Bengkulu.

Menurut Chaer (2007: 175) pembentukan kata secara derivasi tentunya berbeda dengan pembentukan kata secara infleksi. Pembentukan kata secara derivasi membentuk kata baru, kata yang identitas leksikalnya tidak sama dengan kata dasarnya, misalnya, dari kata Inggris sing 'menyanyi' terbentuk kata singer 'penyanyi', dari kata write 'menulis' terbentuk kata writer 'penulis' dan dari kata bunt 'memburu' menjadi kata bunter 'pemburu'. Jelas antara kata sing dan singer berbeda identitas leksikalnya, sebab selain maknanya berbeda kelasnya juga tidak sama, sing berkelas verba sedangkan singer berkelas nomina. Begitu juga dengan kata write dan writer, dan antara kata bunt dan bunter. Contoh dalam bahasa Indonesia dapat diberikan misalnya: dari kata air yang berkelas nomina dibentuk menjadi mengairi yang berkelas kata verba, dari kata makan yang berkelas verba menjadi makanan yang berkelas nomina.

Begitu juga dengan pendapat Chaer (2015: 37) yang mengatakan bahwa dalam proses pembentukan derivasi identitas bentuk yang dihasilkan tidak sama dengan identitas leksikal bentuk dasarnya. Pembentukan kata membeli dari dasar beli adalah sebuah kasus infleksi, tetapi pembentukan kata pembeli dari dasar beli adalah sebuah kasus derivasi. Dasar beli dan kata membeli sama-sama berkategori verba, sedangkan dasar beli dan kata pembeli tidak sama kategorinya, beli adalah verba sedangkan pembeli adalah nomina. Menurut Chaer (2005: 63), pembentukan kata secara derivasi adalah pembentukan kata baru, kata yang identitas leksikalnya tidak sama dengan kata dasarnya. Umpamanya dari kata Inggris sing "menyanyi" terbentuk kata singer "penyanyi". Jelas antara kata sing dan singer perbedaan identitas leksikalnya, sebab lain maknanya berbeda, kelas katanya juga berbeda, sing berkelas verba sedangkan singer berkelas nomina.

Pendapat lain dari Sneddon, (2010: 30) derivasi kata benda mempunyai banyak jumlah imbuhan yang bisa dilampirkan pada kata dasar benda. Prefiks pen-, Prefiks ini dapat dilampirkan pada kata kerja dan beberapa kata benda lain.

\footnotetext{
Menganut $\rightarrow$ penganut

Menonton $\rightarrow$ penonton
} 


\section{Menulis $\rightarrow$ penulis}

Prefiks pe-, Prefiks pe-pada derivasi kata benda menandakan seseorang sedang melakukan suatu tindakan.

$$
\begin{aligned}
& \text { Berenang } \rightarrow \text { perenang } \\
& \text { Bergulat } \rightarrow \text { pegulat }
\end{aligned}
$$

Pada kata sifat prefiks pen- dapat digabungkan pada kata:

$$
\begin{aligned}
& \text { Diam } \longrightarrow \text { pendiam } \\
& \text { Malas } \longrightarrow \text { pemalas }
\end{aligned}
$$

Selain itu prefiks pen-adjektiva dapat digabungkan dengan kata kerja,

Tidur $\rightarrow$ penidur

Lира $\rightarrow$ реlира

Menurut pendapat Lyons (Dalam Putrayasa, 2010: 103) derivasi mendaftar berbagi proses pembentukan kata-kata baru dari kata-kata yang sudah ada (akar, asal), adjektiva dari nomina (seasonal dari season), nomina dari verba (singer dari sing), adjektiva dari verba (acceptable dari accept), afiks-afiks yang dapat membentuk derivasional antara lain: ke-an dalam kebaikan, per-an dalam pertunjukan, pe-an dalam penurunan.

\section{METODE}

Metode yang digunakan dalam penelitian ini adalah metode deskripsi dengan pendekatan kualitatif. Sumber data pada penelitian ini adalah bahasa lisan tuturan bahasa Melayu Bengkulu. Data dalam penelitian ini adalah kalimat yang mengandung verba, nomina dan adjektiva pada bahasa Melayu Bengkulu. Metode pengumpulan data dalam penelitian ini antara lain menggunakan metode simak libat cakap sedangkan teknik pada penelitian ini menggunakan teknik rekam dan teknik catat. Teknik analisis data yang digunakan dalam penelitian ini adalah teknik top down dan bottom up. Teknik top down merupakan teknik yang bersifat membedah yaitu mengkaji unsur yang ada dalam produk sedangkan teknik bottom up adalah teknik yang mengawali proses pembentukan dengan titik tolak intuisi gramatikal temu.

\section{HASIL PENELITIAN DAN PEMBAHASAN}

\section{Hasil}

Sesuai dengan fokus penelitian dan, sajian hasil penelitian beserta pembahasannya dalam penelitian ini berkaitan dengan deskripsi mengenai derivasi bahasa Melayu Bengkulu. Bahasa Melayu Bengkulu yang dianalisis pada penelitian ini yaitu derivasi atau proses pembentukan kata pada setiap kalimat yang mengandung kata verba, nomina, dan adjektiva. Kalimat-kalimat yang mengandung verba, nomina, dan adjektiva tersebut kemudian dianalisis berdasarkan bentuk, fungsi afiks, dan makna.

Bentuk derivasi bahasa Melayu Bengkulu yang diperoleh yaitu derivasi dengan bentuk kata bermakna gramatikal seperti kata, nelpon, makanan, nyacap, mane, bepantn, beselo, ngimami, keributan, pembuek, beotot. sedangkan untuk fungsi afiks pada derivasi Bahasa melayu Bengkulu yaitu mengubah kelas kata, dari nomina menjadi verba yakni prefiks $N$ , prefiks be-, dari adjektiva menjadi verba yakni prefiks te-, gabungan afiks $N$ - dan -kan, dari verba menjadi nomina yakni prefiks te- prefiks pen-, dari adjektiva menjadi nomina yakni prefiks pe-prefiks ke-, konfiks ke-an, dari nomina menjadi adjektiva yakni prefiks be-, dan dari verba menjadi adjektiva yakni prefiks ke-. 


\section{Pembahasan}

[Data 1] Verba yang mengandung prefiks $N$ - dengan bentuk dasar yang terdiri atas nomina dan adjektiva. Berikut analisis kata yang mengandung verba dengan prefiks $N$ -

Malam tadi ado yang nelpon pas diangkek matikannyo, lab berapo kali cak itu, begawe nian manusio banyak ni.

'Malam tadi ada yang menelepon pas diangkat dimatikannya, sudah berapa kali seperti itu, kurang kerjaan sekali manusia banyak ini'

Kata nelpon berasal dari kata telpon, dalam bahasa Melayu Bengkulu seperti berikut:

Telponla kek bunda tu nda leke la nda orang ko la nunggu.

'Telponlah bunda itu nda cepatlah nda orang ni sudah nunggu'.

Prefiks N-pada kata nelpon merupakan unsur yang mendampingi di depan operand (kata dasar) telpon. Kata nelpon bentuk dasarnya adalah telpon. Kata telpon mendapat prefiks $N$ sehingga berubah menjadi nelpon, $N-+$ telpon $\rightarrow$ nelpon. Fonem /t/ pada telpon berubah menjadi fonem $/ \mathrm{n} /$.Kata telpon berkategori nomina. Fungsi prefiks $N$-pada kata nelpon adalah mengubah kelas kata, yakni nomina berubah menjadi verba. Makna dari nelpon adalah berkomunikasi atau memanggil dengan menggunakan pesawat telepon.

[Data 2] Verba yang mengandung prefiks te- dengan bentuk dasar yang terdiri atas nomina dan adjektiva. Berikut analisis kata yang mengandung verba dengan prefiks te-.

Itula laju tegelak ambo nengok nenek tu, dak galak dengar kecek anak cak itula, kecek ambo.

'Itulah langsung tertawa saya melihat nenek itu, tidak mau mendengar kata anak ya begitu, kata saya'

Kata tegelak berasal dari kata gelak yang dalam bahasa Melayu Bengkulu sebagai berikut:

Nak gelak duso pulo kelak, biaso orang la tuo cak itula, kito tuo kelak kalu lebi para lagi dari itu.

'Mau ketawa dosa pula nanti, biasa orang sudah tua seperti itu, kita tua nanti mungkin lebih parah'

Prefiks te-pada kata tegelak adalah unsur yang mendampingi di depan operand (kata dasar) gelak. Kata tegelak bentuk dasarnya adalah gelak. Kata gelak mendapat prefiks te- sehingga berubah menjadi tegelak, te- + gelak $\rightarrow$ tegelak. Prefiks te-muncul di depan bentuk dasar yang dimulai dengan konsonan hambat tak bersuara velar $g$ pada kata dasar gelak. Kata gelak berkategori nomina. Fungsi prefiks te- pada kata tegelak adalah mengubah kelas kata, yakni nomina menjadi verba. Makna dari tegelak adalah rasa senang, gembira, dan lucu dengan suara berderai.

[Data 3] Verba yang mengandung gabungan afiks $N$-dan -kan dengan bentuk dasar yang terdiri atas nomina dan adjektiva. Berikut analisis kata yang mengandung verba dengan gabungan afiks $N$-dan -kan.

Tapi itu bukan cerito slinyo, cuman orang jaman dulu nceritokannyo model itu, mbayangkannyo kito kekiro model itulah.

'Tetapi itu bukan cerita aslinya, hanya orang jaman dulu menceritakannya seperti itu, membayangkannya kita seperti itulah kira-kira'

Kata nceritokan berasal dari kata cerito, yang dalam bahasa Melayu Bengkulu sebagai berikut: 
Tapi itu bukan cerito aslinyo, cuman orang jaman dulu nceritokan nyo model itu,mbayangkannyo kito kekiro model itulah.

'Tetapi itu bukan cerita aslinya, hanya orang jaman dulu menceritakannya seperti itu, membayangkannya kita seperti itulah kira-kira'

Prefiks $N$ - pada kata nceritokan adalah unsur yang mendampingi di depan operand (kata dasar) cerito, sedangkan sufiks -kan adalah unsur yang mendampingi di belakang operand cerito. Kata nceritokan bentuk dasarnya adalah cerito. Kata cerito mendapat gabungan afiks $N$-dan -kan sehingga berubah menjadi nceritokan, $N-+$ cerito + -kan $\rightarrow$ nceritokan. Prefiks $N$ - muncul di depan bentuk dasar yang dimulai dengan konsonan hambat tak bersuara palatal $c$ pada kata dasar cerito dan sufiks-kan muncul di belakang vokal tengah belakang 0 pada kata dasar cerito. Kata cerito berkategori nomina. Fungsi gabungan afiks $N$-dan -kan pada kata nceritokan adalah mengubah kelas kata, yakni nomina menjadi verba. Makna dari nceritokan adalah menuturkan cerita kepada lawan bicara.

[Data 4] Nomina yang mengandung prefiks pe- dengan bentuk dasar yang terdiri atas verba. Berikut analisis kata yang mengandung nomina dengan prefiks pe-.

Pembuekdol tu ado ado di arah bajak, terus di pasar melintang jugo ado, bisa diitung berapo orang dari satu provinsi ko idak banyak.

'Pembuat dol itu ada d arah bajak, terus di pasar melintang juga ada, bisa dihitung berapa orang dari satu provinsi ini'

Kata pembuek berasal dari kata buek yang dalam bahasa Melayu Bengkulu sebagai berikut: Pak. Sabrul, kalo tinggal di Bengkulu ko la dari lahir memang asli orang Bengkulu, kalo buek dolnyo ko mulai taun duoribu itu mulai aktipnyo.

'Pak Sahrul, kalau tinggal di Bengkulu ini sudah dari lahir memang asli orang Bengkulu, kalau buat donya ini mulai tahun dua ribu itu mulai aktifnya'

Prefiks pen- pada kata pembuek adalah unsur yang mendampingi di depan operand (kata dasar) buek. Kata pembuek bentuk dasarnya adalah buek. Kata pembuek mendapat prefiks pen-sehingga berubah menjadi pembuek, pen- + buek pembuek. Prefiks pen- muncul di depan konsonan hambat tak bersuara bilabial $b$ pada kata dasar buek. Kata buek berkategori verba. Fungsi prefiks pen- pada kata pembuek adalah mengubah kelas kata, yakni verba menjadi nomina. Makna dari pembuek adalah orang yang membuat suatu barang, peraturan dan lain sebagainya.

[Data 5] Nomina yang mengandung prefiks ke- dengan bentuk dasar yang terdiri atas adjektiva. Berikut analisis kata yang mengandung nomina dengan prefiks ke-.

Kalo ado apo-apo itu utamakan musyawarah dulu, entah itu di rumah ketuo adat, apo di balai, apo di masjid.

'Kalau ada apa-apa itu tanyakan musyawarah dulu, entah itu di rumah ketua adat, atau di balai, atau di masjid'

Kata ketuo berasal dari kata tuo yang dalam bahasa Melayu Bengkulu sebagai berikut:

Janjian dulu kek orang yang punyo batang kelapo tu, jadi misal ado kelapo yang la tuo tukan, kami janjian kelapo siapo misal ado yang nebang kito gali, biaso orang tu ngasi.

'Janjian dulu sama orang yang punya pohon kelapa itu, jadi misal ada kelapa yang sudah tua itukan, kami janjian kelapa siapa misalkan ada yang menebang kita gali, biasanya orang itu memberinya' 
Prefiks kee-pada kata ketuo adalah unsur yang mendampingi di depan operand (kata dasar) tuo. Kata ketuo bentuk dasarnya adalah tuo. Kata tuo mendapat prefiks ke- sehingga berubah menjadi ketuo, ke- + tuo $\rightarrow$ ketua. Prefiks ke- muncul di depan konsonan hambat tak bersuara alveolar $t$ pada kata dasar tuo. Kata tuo berkategori adjektiva. Fungsi prefiks ke- pada kata ketuo adalah mengubah kelas kata, yakni adjektiva menjadi nomona. Makna dari ketuo adalah orang yang memimpin, rapat, perkumpulan dan lain sebagainya.

[Data 6] Adjektiva yang mengandung sufiks -an dengan bentuk dasar yang terdiri atas verba dan adjektiva. Berikut analisis kata yang mengandung nomina dengan sufiks -an.

Tobo ko banyak. ngelub katonyo jangan nari pakai tabot lagi berek, beotot sayo, laju tobo ko lako nari pakai jari-jari nyo.

'Mereka sering mengeluh, katanya jangan pakai tabot lagi kalau menari berat, berotot saya, jadi mereka memakai jari-jari saja'

Kata beotot berasal dari kata otot yang dalam bahasa Melayu Bengkulu sebagai berikut:

Tobo ko nian kalo nari dak galak bawak tabot,otot nyo sakit keceknyo.

'Mereka ini kalau menari tidak mau membawa tabot, ototnya sakit katanya'

Prefiks be-pada kata beotot adalah unsur yang mendampingi di depan dan operand (kata dasar) otot. Kata beotot bentuk dasarnya adalah otot. Kata otot mendapat prefiks be- sehingga berubah menjadi beotot, be- + otot $\rightarrow$ beotot. Prefiks be- muncul di depan bentuk dasar yang dimulai dengan vokal tengah belakang $o$ pada kata dasar otot. Kata otot berkategori nomina. Fungsi prefiks be- pada kata beotot adalah mengubah kelas kata, yakni nomina menjadi adjektiva. Makna dari beotot adalah mempunyai bentuk tubuh yang kekar.

[Data 7] Adjektiva yang mengandung konfiks ke-an dengan bentuk dasar yang terdiri atas verba dan adjektiva. Berikut analisis kata yang mengandung konfiks ke-an.

Gayo kau sholat subuh bae masih kesiangan.

'Kamu aja sholat subuh masih kesiangan'

Kata kesiangan berasal dari kata siang yang dalam bahasa Melayu Bengkulu sebagai berikut:

Meski la temu tempat kemantin siang tadi la ngecek, harus datang jugo tetap, namo keluargo yo

keluargo adat yo adat.

'Meskipun sudah bertemu di tempat pesta siang tadi sudah ngomong, harus datang juga tetap, namanya keluarga ya keluarga adat ya adat'

Konfiks ke-an pada kata kesiangan adalah unsur yang mendampingi di depan dan di belakang operand (kata dasar) siang. Kata siang mendapat konfiks ke-an sehingga berubah menjadi kesiangan, ke-an + siang $\rightarrow$ kesiangan. Prefiks ke- muncul di depan bentuk dasar yang dimulai dengan konsonan geseran alveolar $s$ pada kata dasar siang dan sufiks -an muncul di belakang bentuk dasar konsonan hambat tak bersuara velar $g$ pada kata dasar siang. Kata siang berkategori nomina. Fungsi konfiks ke-an pada kata kesiangan adalah mengubah kelas kata nomina menjadi adjektiva. Makna dari kesiangan adalah terlalu siang.

[Data 8] Adjektiva yang mengandung prefiks te- dengan bentuk dasar yang terdiri atas verba dan adjektiva. Berikut analisis kata yang mengandung prefiks te-.

Kue lupis tu ado artinyo yang paling ate tu tuban suda tu yang bawa orang yang tehormat lah kekiro di kelurahanitu, sudah tu baru kepala adat.

'Kue lupis itu ada artinya yang paling atas itu tuhan, yang samping bawah orang yang terhormat lah kira-kira, sesudah itu baru kepala adat' 
Kata tehormat berasal dari kata hormat yang dalam bahasa Melayu Bengkulu sebagai berikut: Harusnyo kalo yang lebi mudo nak merokok nyemba dulu bormat kek yang lebi tuo, naa elok sebenarnyokan adat ko.

'Seharusnya kalau yang lebih muda mau merokok menyembah dulu hormat sama yang lebih tua, naa bagus sebenarnya adat ini'

Prefiks te- pada kata tehormat adalah unsur yang mendampingi di depan operand (kata dasar) hormat. Kata tehormat bentuk dasarnya adalah hormat. Kata hormat mendapat prefiks te- sehingga berubah menjadi tehormat, te- + hormat $\rightarrow$ terbormat. Prefiks ter- muncul di depan bentuk dasar yang dimulai dengan konsonan geseran glotal $b$ pada kata dasar hormat. Kata hormat berkategori verba. Fungsi prefiks te- pada kata terhormat adalah mengubah kelas kata, yakni verba menjadi adjektiva. Makna dari terhormat adalah dihormati atau mulia.

\section{PENUTUP}

Berdasarkan analisis derivasi dalam bahasa melayu Bengkulu yang di lihat dari afiks-afiks yang mengubah kelas katanya, maka diperoleh kesimpulan sebagai berikut.

Afiks yang terdapat pada derivasi kelas kata verba yaitu $N$-, be-,te-, me- ke-an, $N$ kan,-i, kan-, $N-i$, peN-an, $N$-i, dimana afiks- afiks ini berfungsi sebapai pengubah dari kelas kata nomina menjadi kelas kata verba diantaranya: ngimami, beselop, beasok, nceritokan, nyacap, nelpon dan dari kelas kata adjektiva menjadi kelas kata verba diantaranya: melenya, mbersikan, mane, melepe.

Afiks yang terdapat pada derivasi nomina yaitu $p e-$, peN-. Per-an, per-, ke-, -an, kean, per-an, peN-an. dimana afiks-afiks ini berfungsi sebagai pengubah dari verka menjadi nomina diantaranya: pelatih, pembuek, pemain, pembeli, dan dari adjektiva menjadi nomina diantaranya: ketuo, penyakit, keributan, kesenian, perbaikan.

Afiks yang terdapat pada derivasi adjektiva yaitu be-, te-, dan ke-an dimana afiksafiks ini berfungsi sebagai pengubah dari verba menjadi adjektiva diantaranya: tehormat, dan dari nomina menjadi adjektiva diantaranya: bepiti, kesiangan, beotot. Peneliti menyadari bahwa penelitian ini kurang sempurna maka dari itu bagi peneliti selanjutnya perlu melakukan penelitian yang lebih mendalam mengenai derivasi bahasa baik ditinjau dari segi bentuk, fungsi, makna maupun kelas kata yang belum diteliti seperti adverbia, pronomina, dan numeralia.

\section{DAFTAR PUSTAKA}

Abdul Chaer. (2005). Sosiolinguistik Perkenalan Awal. Jakarta: Rineka Cipta.

Chaer, A. (2007). Linguistik Umum. Jakarta: Rineka Cipta.

Chaer, A. (2015). Morfologi Bahasa Indonesia. Jakarta: Rineka Cipta.

Putrayasa, I. B. (2010). Kajian Morfologi. Singaraja: Refika Aditama.

Sneddon, J. N. (2010). Indonesian Reference Grammar. University Of Sydney: A\&U Academic. 